\title{
A IMIGRAÇÃO ITALIANA NA CIDADE DE SOROCABA E A EXPERIÊNCIA ESCOLAR NO FINAL DO SÉCULO XIX E INÍCIO DO SÉCULO XX
}

Jefferson Carriello do Carmo

jefferson.carmo@prof.uniso.br

Wilson Sandano

wilson.sandano@prof.uniso.br

Universidade de Sorocaba - UNISO

\section{RESUMO:}

Este trabalho trata da imigração italiana em Sorocaba, nos últimos anos do século XIX e nos anos iniciais do século XX, e sua relação com a educação escolar em Sorocaba. A pesquisa, além da bibliográfica, foi realizada através da consulta de documentos e jornais da época. No período estudado estava ocorrendo, em Sorocaba, o início da industrialização, o aumento da imigração e o crescimento da população urbana, sem o aumento dos benefícios sociais. O trabalho procura mostrar a influência da imigração italiana no desenvolvimento da cidade, bem como a luta pela criação de escolas para a colônia e, também, para brasileiros. Em particular, mostra a criação da escola moderna na cidade.

Palavras-chave: Sorocaba. Movimento anarquista. Educação escolar. Escola Moderna. Imigração Italiana.

\section{ITALIAN IMMIGRATION IN THE CITY OF SOROCABA AND SCHOOL EXPERIENCE IN THE LATE NINETEENTH CENTURY AND BEGINNING OF THE TWENTIETH CENTURY}

\begin{abstract}
:
This work treats of the Italian immigration in Sorocaba, in the last years of the century XIX and in the first years of the century XX, and his/her relationship with the school education in Sorocaba. The research, besides the bibliographical, it was accomplished through the consultation of documents and newspapers of the time. In the studied period it was happening, in Sorocaba, the beginning of the industrialization, the increase of the immigration and the growth of the urban population, without the increase of the social benefits. The work show the influence of the Italian immigration in the development of the city, as well as the fight for the creation of schools for the colony and, also, for Brazilian. In matter, it shows the creation of the modern school in the city.
\end{abstract}

Key-words: Sorocaba. I move anarchist. School education. Modern school. Italian immigration. 


\section{Apresentação}

Os primeiros registros sobre a imigração italiana para a cidade de Sorocaba são de 1885. Quando aqui chegaram foram aproveitados na nascente indústria paulista e nas fazendas de café. Não trouxeram somente sua força de trabalho, mas sua cultura e formas de pensar e agir. Na cidade de Sorocaba, como também em outras cidades, os imigrantes contribuíram para o surgimento de movimentos e associações operárias ligados à produção. Além disso, uma das primeiras atividades realizadas pelos imigrantes foi a fundação de escolas, tendo como objetivo preservar as tradições, os costumes e a língua de origem.

Neste trabalho procuramos verificar as atividades desses imigrantes quanto à sua inserção e contribuição no processo de industrialização; constatar as suas formas de movimentos e associações operárias ligados à produção e, por fim, examinar a questão escolar, com destaque às ligadas ao "ensino livre" na cidade de Sorocaba entre os anos de 1900 - 1920. Toda esta preocupação foi norteada pelo conceito de "experiência" entendida como um processo realmente vivido pelos seres sociais e que modifica efetivamente a consciência social e processo educacional.

\section{Imigração e industrialização em Sorocaba}

O início do processo fabril, na cidade de Sorocaba, ocorreu com a experiência do fazendeiro de algodão Manuel Lopes de Oliveira que instalou, em 1857, uma fábrica para descaroçar, cordar, fiar e tecer algodão em tecidos grossos empregados nas roupas dos escravos, operada com apenas "quatro operários (escravos) que produziam trezentas onças de fio por dia" (RIBEIRO, 1998, p. 24, CARMO, 2006). Aliás, esse processo mecânico de maquinas de descaroçar algodão, segundo Canabrava (1984), identifica Sorocaba como uma das primeiras cidades interioranas a fazer uso desse recurso.

Nessa primeira experiência, as dificuldades enfrentadas por Manoel Lopes de Oliveira foram a falta de mão-de-obra especializada e a alta do preço do algodão, que levaram ao fracasso dessa primeira tentativa.

Em 1873, com a recuperação das exportações norte-americanas para a Europa, foi criada uma situação favorável ao estabelecimento de fábricas nos centros produtores de algodão, o que proporcionou, também, o aumento da imigração para a cidade e facilitou o recrutamento de trabalhadores especializados.

O papel desempenhado por estes [os imigrantes] no primeiro surto de industrialização foi crucial, sob vários aspectos: pela ampliação do mercado de trabalho e de consumo; pela preferência em inverter a poupança no setor comercial e industrial, tendo-se em conta as dificuldades impostas ao acesso à propriedade da terra; pelo impulso dado ao crescimento da Cidade de São Paulo. (...) também que a força de trabalho estrangeira não veio substituir simplesmente a mão-de-obra escrava, mas representou um grande aumento do potencial de trabalho, destinado a atender aos requisitos de uma economia em plena expansão. (FAUSTO, 1976:17)

Essa situação trouxe novos extratos sociais emergentes, criando e concretizando novas relações de produção entre o capital e trabalho. Essa relação toma lugar das velhas relações entre proprietários e escravos e vem consolidar uma nova situação econômica e social.

Em Sorocaba essa situação já aparece no início da construção da ferrovia, em 1872, e, depois, na fábrica Nossa Senhora da Ponte, em 1882 (SAES, 1981; RIBEIRO, 1988). Como exemplo desses novos tempos, pode-se indicar o surgimento dos locais de moradia 
desse operariado imigrante, as chamadas vilas operárias, que, geralmente, ficavam próximas ao local de trabalho. A fábrica de Votorantim, localizada a 6 quilômetros de Sorocaba, construiu praticamente uma 'cidade operária', que, em 1913, acomodava 3.000 operários e tinha no seu âmbito jardins públicos, clubes, escolas, lojas e iluminação elétrica (DECCA, 1987).

Nos anúncios dos vários jornais1 da cidade pode-se verificar que, nos anos de 1880, Sorocaba, motivada pelo impulso industrial, passou a atrair imigrantes italianos e alemães, que exploravam o comércio urbano através das manufaturas e pela diversificação dos investimentos. O italiano Alferio Malzone fabricava calçados; Antonio Faizano, macarrão; Mathias Baddini, café em pó; Domenico Guli, massas; José Luchesi, calçados; Francisco Matarazzo, banha. Os alemães mantinham o seu negócio local, como as fábricas de cerveja de Augusto Boemer, Faust e Schimming, Luiz Bücher, de Lausberg e Raszl; além da fábrica de colchões de Eduardo Müller e de louças de Joana Katzer. A cidade atraía, ainda, pessoas ligadas a outros tipos de serviços, como o fotógrafo italiano Italo de Angelis, que passara na cidade em março de 1882.

Entre as profissões o censo indicava os seguintes dados: lavradores, 2.456; negociantes, 338; empregados públicos, 22; padres, 5; advogados, 5; solicitadores, 2; médicos, 2; farmacêuticos, 2; relojoeiros, 3; ourives, 5; fotografo, 1; pintores, 18; músicos, 23; tipógrafos, 3; alfaiates, 52; marceneiros, 27; carpinteiros, 111; seleiros, 72; sapateiros, 55; serigoteiros, 52; armadores, 2; trançadores, 24; chapeleiros, 27; ferreiros, 97; pedreiros, 61; laoeiros, 8; fogueteiros, 19; barbeiros, 2; ferradores, 8. (Jornal Ypanema de 21/11/1872)

Muitos dos imigrantes e comerciantes começaram a investir seu capital em outras atividades industriais. Foi nos anos de 1880 que se realizou a instalação da indústria de grande porte na cidade, representada pela indústria têxtil. Anteriormente a esse investimento as atividades fabris eram de cunho manufatureiro, incluídas as indústrias de fabricação de redes, cestas, tranças, etc., muito comuns entre as classes desprovidas de meios de produção da cidade. (Diário de Sorocaba 26/10/1890)

No caso específico da vinda dos italianos, ela está atrelada a várias insurreições de caráter nacional, tendentes à unificação da Itália, que se concretizou com a formação do Primeiro Parlamento Italiano em 1861, ano em que foi promulgada a Constituição do Reino da Itália. (CENNI, s/d; DOLLÉANS, 1977). Estes imigrantes trouxeram consigo, para o Brasil, experiências de luta e reivindicações trabalhistas (RODRIGUES, 1984; BIONDI, 1998).

Aqui chegando, criaram associações, nas quais realçavam suas próprias opiniões quanto aos direitos sociais para os mais humildes nativos e menos para os humildes de terras alheias. Traziam em seus ideários as novas idéias presentes nos meios operários e tinham como objetivo fixar, o nacionalismo e o patriotismo em relação a terra natal. Para eles, a voz da idéia é a palavra; seu eco, o jornal, folhetos e revistas que cumprem, na cidade, tarefa importantíssima na disseminação das idéias, das experiências e das reivindicações dos trabalhadores e a condição operária, na cidade. (BONADIO, 2004; ARAUJO NETO, 2005, CAVALHEIRO, 2001; MARTINS, 1981; RODRIGUES, 1974; SILVA, 1976).

Em Sorocaba, o jornal O Operário, de cunho socialista e anarquista2, além de mostrar o progresso representado pela indústria3, também denunciava os excessos das jornadas de trabalho.

Com o lema do progresso, as fábricas impunham um ritmo de produção, em que as jornadas de trabalho de 12,13,14 e até 15 horas diárias como no caso das fábricas Santa 
Maria, Santa Rosália e Fonseca. Em alguns casos, o chamado "serão" era estendido até a madrugada. O jornal denunciava que essas jornadas de trabalho muito longas impediam que os menores em serviço freqüentassem as escolas noturnas, contribuindo para o aumento do número de semi-analfabetos (O Operário, 02/10/1909).

Outro aspecto denunciado pelo jornal eram os castigos corporais, aos menores, realizados pelos contramestres e fiscais das seções da Fábrica N. S ${ }^{a}$. da Ponte (O Operário, 12/12/1909). O trabalho menor também era utilizado nas fábricas, porém combatido e denunciado. Nas longas jornadas de trabalho existia a má alimentação, o cansaço em demasia dos pequenos operários de 10 e 12 anos, que trabalhavam como ajudantes dos operários principais, causando-lhes diversos acidentes, algumas vezes graves. (O Operário, 24/07/1910)

Esses e outros fatos (Cf. CARMO, 2005; 2006; 2007), remetem-nos a considerar que a imigração para a cidade de Sorocaba e a mudança do processo de produção com a implantação das indústrias caracterizada pelas relações entre capital e trabalho em que estabelecem a obrigatoriedade da venda do único bem que o trabalhador imigrante e local possui a força de trabalho. É exatamente durante esse exercício cotidiano que se desenvolvem algumas das mais (senão a mais) importante contradição das relações sociais - as relações contraditórias do trabalho, que podem ser contempladas pela organização das sociedade dos trabalhadores e pela experiência escolar.

\section{As associações imigrantes italianas}

$\mathrm{Na}$ gênese do processo de industrialização em Sorocaba, como já registramos, houve a criação de várias associações das mais variadas posições políticas e ideológicas. Não podemos deixar de considerar que as divergências entre essas correntes oriundas das lutas ideológicas já eram travadas no país de origem e foram trazidas para o Brasil e suas províncias. (Cf. GALLI, 1998; BRESSO, CEREJA, GARIGLIO, 1989; GOBETTI, 1995; BATALHA, 1995; RODRIGUES, 1988, 1972; FAUSTO, 1976)

Segundo ARAUJO NETO (2005) é possível já constatar, no mínimo dois aspectos relevantes dessas associações quanto à sua organização:

1) eram compostas por imigrantes, mostrando que no Brasil muitas vezes (mas nem sempre), as primeiras iniciativas de se organizarem sociedades operárias partiram dos estrangeiros;

2) o próprio caráter contraditório que elas possuíam, sendo, no caso da primeira, uma homenagem permanente a um monarca, e, no caso da segunda, tendo um elemento proeminente da colônia em sua diretoria, que, no ano seguinte, iniciaria atividades empresariais que o transformariam em grande capitalista e, ao mesmo tempo, ser uma sociedade operária. (ARAUJO NETO, 2005:48)

No caso de Sorocaba, que não era diferente do que acontecia em outras cidades e estados, podemos citar os movimentos e associações ligados aos trabalhadores, na sua maioria compostas por imigrantes europeus, cuja função principal era o auxilio mútuo. Essas associações estavam ligadas aos ofícios e à proteção mutualista, que traziam, também, do Velho Mundo as novas idéias que rondavam os meios operários.

As primeiras alusões sobre as associações italianas em Sorocaba ligadas aos operários foram a Societá Operaria Umberto I, constituída em 11/10/1885 de cunho monárquico. "Essa era composta por mais de 200 italianos da colônia de Sorocaba é uma das mais importantes, entre as cidades, segundo a ordem desta no império" (IRMÃO ALEIXO, 1999: 320). Essa associação era composta pelo Presidente "João Cozzetti; Vice- 
Antonio Catalano; $1^{\circ}$ Sec. Franscico Matarazzo; $2^{\circ}$ Sec. José Válio; $1^{\circ}$ Tes. Angelo Rizzo; $2^{\circ}$ Tes. Franscisco Cozzetti" (Id., Ibem). Há registros, ainda, nesse mesmo período da Societá Operaria Italiana di e Mutuo Soccorso e Beneficenza só para italianos (Cruzeiro do Sul, 22 de Nov. 1905). Era composta pelo Prof. Constabile Sergio, da Scuola Coloniale Italiana e da Societá Italiana de Mutuo Socorro (Cruzeiro do Sul, 12 de Out. 1904), presidida por C. Matarazzo e pelo professor da escola da cidade de Votorantim José Rizzo. Esta associação tinha caráter "garibaldino" de cunho republicano. A Societá Operaria Umberto I detinha a influência sobre a elite sorocabana e a Societá Operaria Italiana di e Mutuo Soccorso e Beneficenza detinha a mesma influência e interesses dos mesmos grupos pertencentes às colônias, tendo um caráter mais nacionalistas do que de classe.

Num primeiro momento, o que podemos verificar quanto a essas sociedades é que em seu bojo havia uma necessidade da organização em torno do nacionalismo patriota, embora essa fosse divergente devido às posições políticas que ambas assumiam. A Societá Operaria Umberto I, de cunho monárquico e a Societá Operaria Italiana di e Mutuo Soccorso e Beneficenza, de expressão garibaldiana, tinham como princípio a ajuda mútua para os operários. Essa preocupação de organização operária é vista antes mesmo da República no Brasil, o que nos remete a inferir que essas sociedades operárias tinham um caráter tênue quando pensada na ótica das lutas de classes. Embora isso ocorresse pela própria incongruência da própria classe operária que ainda estava em formação constituíam em um caráter muito mais nacionalista do que contraditório de classe presente na ideologia proletária.

Isso, porém começa a tomar outros rumos com o progresso da cidade, visto nas primeiras fábricas com a chegada de mais imigrantes de várias nacionalidades que trazem consigo, não só as experiências operárias, mas também de luta por melhores condições de salário e de trabalho. Nesse período acentuam-se as contradições entre trabalho e capital, através das organizações operárias, que são vistas no início do século $\mathrm{XX}$, como um perigo para os industriais e comerciantes. Esse sentimento de perigo era registrado nos discursos dos socialistas e anarquistas sem, contudo, descartar as greves que foram realizadas nas últimas décadas do XIX, como na fábrica de chapéus de Pereira \& Villela, nos anos de 1890, e as reivindicações dos trabalhadores do comércio pela redução da jornada de trabalho, em 1888 (Diário de Sorocaba, 13 Nov.1888). As paralisações dos trabalhadores em diversas regiões e principalmente na capital federal fizeram com que os donos do capital ficassem mais atentos com a organização operária.

Embora a história mostre que os donos dos meios de produção controlavam a imprensa e outras instituições sociais, no caso de Sorocaba, constata-se que vieram atacar não só todas as formas políticas que eram contraditórias ao progresso, mas a observar melhor algumas das organizações operárias que surgiram na virada do século. Alguns republicanos descontentes com o governo e opositores da política municipal passam incutir, em algumas organizações operárias, suas posições políticas o que propicia a abertura de espaço na imprensa local em nome do "progresso da nação". (Cruzeiro do Sul, Sorocaba, 13 de Jan. 1904).

Embora bastante valorizadas nos discursos, estas associações não exerceram maior atração junto aos operários locais. Há registros que só 200 trabalhadores aderiram à Sociedade Beneficente União Operária. (Cruzeiro do Sul, 04 de Jan. 1905), que funcionava através das mensalidades dos associados e se situava uma sede na Rua São Bento (Cruzeiro do Sul, 19 de Out. 1904) e que no ano seguinte foi transferida para a Rua do Rosario, no 26 (Cruzeiro do Sul, Sorocaba, 19 de Jul. 1905). Seu presidente, Pedro de Mello Pacheco, aproximava-se da alta sociedade sorocabana e, contraditoriamente, 
revogava e conciliava a união dos operários com o patrão e propunha a negação do socialismo e anarquismo. No primeiro ano de sua existência, em 1904, a União Operária era vista com alguns olhos desconfiados, principalmente dos operários. Logo depois da inauguração, uma carta enviada à redação do Jornal Cruzeiro do Sul assinado pelo pseudônimo "Um Operário" descreve:

Fundou-se a Sociedade Operaria em janeiro. Muitos enthusiastas adheriram á ella na fundação, outros depois de a estudar.

A propaganda pró e contra já diminuiu de intensidade.

Muitos operarios tem medo de unirem-se, dizendo que os patrões os olharão como a inimigos.

Não há tal. E' preciso que se comprehenda que a sociedade iniciada tem por fim a beneficencia e a instrucção, nada poderá ella fazer contra os patrões.

Nestas épocas em que o deleterio socialismo vae solapando o operariado, sugando aos poucos sua lealdade no serviço, vemos repudiadas todas as idéias de união.

$\mathrm{O}$ operario teme as consequencias de um socialismo mal entendido, de um anarchismo filho da dynamite e do assassinato.

E' preciso que os dois mil e tantos operarios de Sorocaba comprehendam para que devem se unir. E' preciso que a associação repudie o anarchismo e o Socialismo. (Cruzeiro do Sul, 27 de Fev. 1904)

Esse repúdio, todavia, não acontece na sua integralidade, quando olhado pela ótica do movimento operário, o que ocorre é que na virada do século no Brasil o socialismo possuía vários adeptos, militantes que vieram de vários movimentos europeus, principalmente da Itália. (Cf. BATALHA, 1995) Na cidade de Sorocaba nos movimentos abolicionistas e republicanos muitos de tendências socialistas ficaram desiludidos com a República e migraram para outro tipo de socialismo que ainda poucos conheciam. Isso é possível a verificação através das formas de propagação da imprensa escrita no início do século.

No ano de 1896, com uma grande festa, funda-se a Sociedade Beneficente dos Empregados da Companhia União Sorocabana e Ituana dos operários de Sorocaba.

Em 1897, o jornal A Voz do Povo, de 29 de janeiro, dá a conhecer o surgimento de um "órgão legítimo" para a defesa da classe operária de Sorocaba, A Conquista do Bem, que se apresentava como órgão do Partido Democrata Socialista na cidade. (BONADIO, 1992)

No ano de 1897 surge outra publicação política destinada a propagandear o socialismo, a revista $O$ Fim do Século, redigida por Arthur Silva, sob o pseudônimo de Isaltino G. Costa. Em seu subtítulo aparece: "em favor do Socialismo, Cosmopolitismo e Espiritismo". A preocupação da revista é tornar visíveis as propostas socialistas, embora tivesse um caráter extremante passivo quanto a um posicionamento político frente à classe operária - em suas publicações visava reformas e benefícios a todo gênero humano. Em seu conteúdo havia um determinado ecletismo de posição intelectual, caracterizado pelas mais variadas publicações e pelas diversas formas de opinião, sem observância alguma de uma linha rígida de pensamento. Há publicações de socialistas como Alicare Cypriani, textos de anarquistas como Kropotkin - A Conquista do Pão - às publicações religiosas kardecistas.

O próprio subtítulo da revista trás este ecletismo, Em favor do Socialismo, Cosmopolitismo e Espiritismo, que reúne elementos doutrinários de origens diversas que não chegam a se articular em uma, em seu conteúdo em uma unidade sistemática Revista HISTEDBR On-line, Campinas, n.33, p.109-121, mar.2009 - ISSN: 1676-2584 
consistente. Embora não fosse notável o posicionamento político-partidário definido da revista, era evidente a aversão ao jesuitismo e a defesa por escolas leigas e gratuitas, que foi um posicionamento também assumido pelos anarcossindicalistas. (Cf. CARMO, 2007)

Há várias evidências de que o socialismo em Sorocaba, após inúmeras investidas, não conseguiu firmar-se na cidade, embora haja diversas publicações que trazem a cogitação da criação de Diretórios e Centro Socialista. No jornal A Conquista do Bem a menção da criação de um Centro Socialista, citado, também pelo Almanaque de Sorocaba de 1903, como sociedade política. Há registros de várias sociedades políticas e operárias em Sorocaba entre 1902 - 1904. (Cf. Almanach de Sorocaba, 1903; Almanach de Sorocaba 1904).

A presença socialista é, ainda, marcada por algumas conferências nos anos de 1902 e 1903, sendo os oradores: "Benjamin Motta (1902); Paschoal Cilento (jan. 1903) e Alceste de Ambrys (mar. 1903)". Houve festas promovidas pelos operários, cuja finalidade era comemorar o "natal dos deserdados". O que favoreceu, ainda que em pequenas proporções, uma tomada de consciência por parte do operariado que também prepararam um ambiente propício, para a aceitação de novos ideais políticos, voltados à questão social.

Nos anos seguintes a estes, ocorre o crescimento do movimento operário devido ao aumento da massa proletária. Há estudos que identificam que as próprias condições materiais propiciavam uma maior agitação do meio proletário. Porém, foram os anarcossindicalistas e anarquistas que assumiram a vanguarda do movimento, conquanto os socialistas continuassem presentes, sendo esses, também de nacionalidade italiana.

\section{A instituição escola italiana}

Seguir as sendas trazidas e deixadas pelos imigrantes italianos no Brasil sobre a questão escolar é de fundamental importância para compreensão das concepções de escola, educação e ensino que tinham e estavam propondo para os seus patrícios na nova pátria. Provavelmente o caminho a ser percorrido, dentre outros, quando pensamos em imigração italiana é a proposta educacional centrada em um novo homem para uma nova sociedade. (Cf. BAKUNIN, 1990 e outros). É no cerne dessa preocupação que se encontra a importância de se constituir as "escolas laicas e livres". Essa é uma proposta, no início do século XX no Brasil encontra nos índices de analfabetismo. As poucas escolas que existiam eram freqüentadas pelas famílias privilegiadas, pois eram as que tinham condições de estudar, tinham tempo e disponibilidade, condições de adquirir materil escolar, etc. As crianças das famílias de trabalhadores, a partir dos cinco anos de idade, ou iam para a lavoura ou iam para a fábrica. (RODRIGUES, 1984)

Um olhar para os pedagogos que defendiam as "escolas laicas e livres" vinculavam essa concepção educacional a revolução social, e ao processo de consolidação da ordem social libertária através de um programa educacional libertário. ${ }^{4}$ Essa preocupação era contrária a educação tradicional, cujo procedimento era preparar os trabalhadores para que aceitassem sem contrariar, a ordem estabelecida. Essa educação ensina os valores sociais e a moralidade da burguesia. Ela ensina através de uma metodologia baseada no autoritarismo e repressão, que contrariava a compreensão que advinha dos anarquistas quanto às escolas livres. (MORIYÓN, 1989)

Nesse sentido a proposta de escola anarquista formula uma pedagogia contrária ao exercício do poder aponta para uma educação antiautoritária, um ensino integral, e a 
educação para a revolução, norteada pela premissa de promover um relacionamento grupal baseado na confiança e na cooperação mútua em que seria a base de uma sociedade ácrata.

$\mathrm{O}$ trabalho de educação não visava simplesmente o desenvolvimento individual através do estudo, pelo contrário, a educação era proposta dentro de um objetivo de transformação social em que os trabalhadores deveriam se preparar coletivamente para se apropriar do saber, que até então, tinha sido monopólio das classes dirigentes. Deveria haver, portanto, uma íntima relação entre a instrução popular e a transformação social revolucionária. (Cf. MORIYÓN, 1989; BAKUNIN, 1990; LUIZZETTO, 1987).

$\mathrm{Na}$ teoria anarquista havia a compreensão de que a escola não deveria ser disciplinadora e que tampouco nela devesse existir o espírito de obediência e submissão. A nova escola deveria ser laica e privada, pois tanto a Igreja quanto o Estado eram considerados como os pilares de sustentação dos privilégios de uma classe social dominante e repressora. Com esse entendimento os anarquistas passaram a fundar por todas as partes escolas livres com o objetivo de alfabetizar os operários e seus filhos, utilizando-as como instrumento de abertura para novas perspectivas dos trabalhadores. Como indica Rodrigues (1984), na primeira década do século XX, na cidade de São Paulo foram fundadas várias escolas que eram norteadas pela preocupação educacional dos anarquistas. A escola Dante Alighieri, no Bairro do Brás, por Luigi Basile, com o propósito de realizar um trabalho de alfabetização dos italianos e brasileiros da região. Alfabetizar era criar as condições necessárias para que o trabalhador começasse abrir os olhos e se levantar contra a dominação política. Além disso, alfabetizar era uma coisa indispensável para que os trabalhadores pudessem começar a ler e assim aprender a filosofia anarquista. Essa preocupação de alfabetizar os trabalhadores foi muito intensa no início do século em que esse trabalho ocupava literalmente o cotidiano dos trabalhadores. Realizavam-se aulas em casa, nos locais de trabalho, nos intervalos das jornadas de trabalho, nas sedes das associações, etc.

O crescimento dessa atividade de formação dos anarquistas impulsionou a criar posteriormente escolas em prédios apropriados, desenvolvendo-se aí as chamadas "escolas modernas". Os anarquistas fizeram um trabalho teórico da revisão do papel da escola e da metodologia pedagógica. Dentre os vários pensadores libertários destacamos dois: Paul Robin, fundador da dominada Escola Integral e Francisco Ferrer, fundador da dominada Escola Moderna ou Escola Racionalista, este último teve enorme repercussão no Brasil. (Cf. JOMANI, 1990; TRAGTENBERG, 1978)

A concepção de escola, de Robin, enfatizava o processo de aprendizagem através da atividade e do trabalho do educando "e do direito que cada homem tem, quaisquer que sejam as circustâncias do seu nascimento, de desenvolvler, da forma mais completa possível, todas as faculdades físicas e intelectuais. Estas últimas palavras definem a educação integral" (MORIYÓN, 1989:88), que reúne segundo Robin três características: educação física; educação intelectual e educação moral. (Apud. DOMMANGET, 1974)

Outro aspecto relevante do pensamanto de Robin é com referência o trabalho como o fundamento da educação, nesse sentido, acentua que na sociedade o trabalhador que produzia para toda a sociedade era, portanto, o núcleo gerador de todas as riquezas. A produção era a própria vida do homem, portanto uma educação ligada à vida deveria, naturalmente, levar em conta a atividade produtiva do homem.

Quanto à proposta da Escola Moderna ou Racionalista de Francisco Ferrer (18591909), esclarecem Raynaud e Ambauves (1978) havia uma proposta de co-educação com grupos heterogêneos, salas de aulas compostas por ambos os sexos e de indivíduos oriundos de diferentes classes sociais. Ensino racionalista quer dizer ensino que tem como 
meio a razão e como guia a ciência; como esta ainda não disse a última palavra sobre qualquer assunto, resulta que o ensino racionalista não tem programa fixo.

Essas experiências anarquistas de educação encontraram eco, no Brasil, nas mais diferentes cidades.

Quanto às escolas italianas na cidade de Sorocaba constata-se, pela imprensa local e pela sua historiografia, do final do século XIX e início do século XX, vários registros que caracterizam e mostram a inserção dessas escolas, na cidade. É notável que elas aconteceram pela imigração dos italianos vindos para o trabalho industrial e para as oficinas da estrada de ferro da região.

Nesses registros encontramos no Jornal A Cidade de Sorocaba, 14/01/1909, a citação da mais antiga escola italiana chamada de Scola Italiana 'Dante Alighieri', que estava situada na colônia italiana em Sorocaba e foi fundada pela Sociedade Operária de Mútuo Socorro em 1885, funcionava à rua do Hospital, $\mathrm{n}^{\circ} 7$, e destinava-se aos filhos dos associados, cuja frequiência era de aproximadamente 30 alunos. Esse jornal, ao comentar sobre a escola, no ano de 1909, dizia:

(...) que a sua localização era na "rua Mons. João Soares, $n^{\circ} 26$ e tinha por finalidade ministrar para a juventude estudiosa a educação moral e intelectual, segundo o programa do governo, recentemente recebido, era extinguir o número de analfabetos, incentivando-os a tomar o caminho da virtude e do conhecimento. O programa era composto pelas seguintes disciplinas, línguas: italiano, latim, francês e português, bem como música, caligrafia, aritmética, geometria, geografia, história da pátria, eclesiástica e natural, os livros eram distribuídos gratuitamente. (Jornal A Cidade de Sorocaba, 14/01/1909)

Embora não encontremos registros mais explícitos quanto às atividades dessa escola podemos inferir, pela historiografia, que seu objetivo era alfabetizar os italianos e brasileiros. No entanto, no ápice de seu desenvolvimento imposto pelo seu fundador, na cidade de São Paulo apropria-se da condição de Universidade Livre, dentro da concepção racionalista de Francisco Ferrer. Ferrer entendia que o ensino, seja ele acadêmico ou não, deve tratar de uma educação não neutra, mas articulada através de uma escala de valores que não reflita simplesmente as grandes declarações de princípios, mas também a vida cotidiana e a própria organização da escola.

O jornal Diario de Sorocaba, de 13/10/1888, trouxe uma nota parabenizando a Societá Operaria Italiana Umberto I pela criação de uma escola primária para o ensino diurno, para os filhos dos associados e, em anexo a este curso, outro, trimestral, para os adultos da colônia. Esse importante passo dado por essa associação recebe elogios do jornal:

Necessariamente uma associação não pode visar um fim mais esplendidamente grandioso que a instrução publica. Preparar o espírito dos homens, equivale preparar a nação desde seus alicerces, conduz o homem ao conhecimento da própria existência. (O jornal Diario de Sorocaba de 13/10/1888)

Essa preocupação com o ensino trazido pelos italianos, em Sorocaba toma corpo, especialmente no que se refere à importância da escola e o que essa deveria representar para o operariado no início do século XX. 
O jornal O Operario, cuja preocupação era ser "orgão de combate" da classe operária e que tinha como missão "defender a legião dos oprimidos que constitui a riqueza universal", trazia, em abril de 1910, uma nota intitulada Oreste Ristori, dizendo:

Esteve nesta cidade, e deu-nos o prazer de ouvir a sua eloqüente palavra, o ilustre orador cujo nome nos serve de epígrafe, discutindo sobre vários pontos referentes à escola moderna, demonstrando de um modo claro e preciso as vantagens do ensinamento único racional, o único verdadeiro, o único digno de ser ministrado aos nossos filhos, para que não sejam amigos de padres e de confessionários (O operário, 24/04/1910).

Em 1909, houve o movimento para a criação da Escola Moderna, inspirada em Francisco Ferrer. Foi criada uma comissão

Pró-Fundação da Escola Moderna, em São Paulo, que passou a trabalhar duro, tanto no interior como na capital, no intuito de angariar fundos. Orestes Ristori, por exemplo, saiu pelo interior do Estado realizando palestras, exibindo filmes etc.; ao mesmo tempo distribuía listas de subscrição em favor da Escola Moderna (GHIRALDELLI JR,1987: 132).

A presença de Orestes Ristori, na cidade de Sorocaba, teve esse objetivo, que foi aceito no meio operário.

Há registros de publicação de palestras realizadas por adeptos da Escola Moderna, cujo conteúdo era sobre os "novos métodos de ensino". Foram publicados, também, os Estatutos Gerais da Liga Internacional para a Educação Racional da Criança, que, entre outras coisas, enumerava alguns princípios que deveriam ser obedecidos pela Escola Moderna, como o apego ao "ensino experimental e científico", a liberdade, os ensinamentos da "moderna psicologia", dentre outros. Esses princípios, de forma geral, foram aceitos não só pelo movimento operário, mas vários segmentos sociais que eram simpatizantes a um ensino cientificista. Na cidade de Sorocaba, por exemplo pelos maçons, que apoiavam a esse tipo de escola. (Cf. ALEIXO IRMÃO, 1999: CARMO, 2006)

De fato, ou por vínculo com a colônia italiana, ou mesmo por simpatia a qualquer tipo de pensamento modernizante, uma boa quantidade de pessoas, das mais distantes localidades do interior de São Paulo, colaboraram com a criação da Escola Moderna.

Em Sorocaba, há o registro de uma escola o filho de anarquistas, localizada na Chácara de Vicente de Caria ${ }^{5}$, no bairro da Caputera, nos anos da década de 1910.

Na chácara do Vicente havia uma escola: Angelina Soares (irmã de Florentino de Carvalho, na época em que viveram na rua Bresser, no Brás, São Paulo) foi professora, por um bom tempo, dos filhos dos anarquistas da comunidade. (RODRIGUES, 2005, p. 49-50)

Finalmente, há o registro da Escola Noturna da Liga Operária de Sorocaba, escola esta fundada em 1912. Segundo as informações obtidas, esta foi uma escola que empregava métodos semelhantes aos da escola moderna (TUDO..., 2008) ${ }^{6}$.

\section{Considerações finais}

Verificou-se que o papel desempenhado pelos imigrantes italianos na primeira fase do processo de industrialização na cidade de Sorocaba foi fundamental pelos seguintes motivos: houve uma crescente ampliação do mercado de trabalho, do consumo, de investimentos no setor comercial e industrial, que determinou o crescimento de mão-de- 
obra na cidade o que representou não só a substituição da mão-de-obra escrava, mas o aumento do potencial de trabalho destinado a atender aos requisitos de uma economia em plena expansão.

Nesse processo de industrialização constatou-se a criação de várias associações das mais variadas posições políticas e ideológicas, mas que em seu cerne objetivavam organizar e formar as associações de trabalhadores imigrantes em Sorocaba, cuja função principal era o auxilio mútuo por estarem, nesse período, ligadas aos ofícios. Essas associações, no Brasil, nem sempre tinham essa iniciativa de estrangeiros, mas todas tinham uma estreita relação com os operários, embora constata-se que na constituição dessas associações há também um caráter nacionalista.

Por fim, verificou-se que no centro dessas organizações estava a inquietação da instituição escolar. Os registros mostram que tanto São Paulo quanto em Sorocaba essas instituições são do tipo "escolas laicas e livres", cuja proposta centrava-se na revolução social, e ao processo de consolidação da ordem social libertária através de um programa educacional libertário.

\section{Referências}

ARAÚJO NETO, Adalberto Coutinho de. Sorocaba operária: ensaio sobre o inicio do movimento operário em Sorocaba 1897-1920. Sorocaba, SP: LINC, 2005.

BADDINI, Cássia Maria. Sorocaba no império: comércio de animais e desenvolvimento urbano. São Paulo: Annablume - Fapesp, 2002.

BAKUNIN, Mikhail. A instrução integral. São Paulo: Imaginário, 2003.

BATALHA, Claudio H. M. A difusão do marxismo e os socialistas brasileiros na virada do século XIX. In: MORAES, João Quartim de. ( Org.) Historia do Marxismo no Brasil. Vol. II. Os influxos teóricos. Campinas, SP: Editora UNICAMP, 1995.

BIONDI, Luigi. Anarquistas italianos em São Paulo. O grupo do jornal anarquista La Battaglia e a sua visão da sociedade brasileira: o embate entre imaginários libertários etnocêntricos. Cadernos AEL, Anarquismo e Anarquistas, n.8/9, 1998.

BONADIO, Geraldo. Sorocaba: a cidade industrial (espaço urbano e vida social sob o impacto da atividade fabril). Sorocaba, SP: Geraldo Bonadio, 2004.

BONADIO, Geraldo. O partido democrata-social e o jornal "A conquista do bem, 1897'. Sorocaba, SP: Academia Sorocabana de Letras, 1992.

BRESS, P.; CEREJA, F. ; GARIGLIO, B. (Orgs.) Politica e instituzioni in Italia dall unità fascismo. Torino: IL Segnalibre, 1989.

CANABRAVA, Alice P. O algodão em São Paulo: 1861-1875. 2.ed. São Paulo: T. A. Queiroz, 1984

CARMO, Jefferson Carriello do. O jornal 'O Operário' e as relações de trabalho na gênese da industria têxtil na cidade de Sorocaba. SAECULUM, Revista de História. João Pessoa, PB, n. 16, p. 119-127, jan/jun, 2007.

Revista HISTEDBR On-line, Campinas, n.33, p.109-121, mar.2009 - ISSN: 1676-2584 
A fábrica Têxtil em Sorocaba, imprensa operária e educação nos anos de 1889-1914. Revista do Centro de Educação e Letras Campus de Foz do Iguaçu. UNIOESTE: Campus Foz do Iguaçu. V. 8, n. 9, p. 23-37, 2006.

; RICCI, Jamer. Indústria em Sorocaba no tempo dos visionários. Cadernos de História. Sorocaba/SP: Uniso, v. 1, no 1, p. 49-53, 2005.

CAVALHEIRO, Carlos Carvalho. Salvadora! Sorocaba SP: LINC, 2001.

CENNI, Franco. Italianos no Brasil. São Paulo: Livraria Martins Editora, S/d.

DOLLÉANS, Édouard. Storia del movimento operaio 1830-1871. Vol. 1. Firenze: Nuova Biblioteca, 1977.

DOMMANGET, Maurice. Os grandes socialistas e a educação de Platão a Lenin. Portugal: Europa-Amárica, 1974.

FAUSTO, Boris. Trabalho urbano e conflito social. São Paulo: Difel, 1976.

GALLI, Giorgio. I partiti politici in Itália 1861-1943. Torino: UTT libreria, 1998

GHIRALDELLI, Jr Paulo. Educação e movimento operário. São Paulo: Cortez: Autores Associados, 1987.

GOBETT, Piero. La rivoluzione Liberale: sagio sulla lotta política in Italia. Torino: Einaudi, 1995.

IRMÃO, Aleixo José. A perseverança III e Sorocaba: da fundação à proclamação da república. Sorocaba, SP: Fundação Ubaldino do Amaral, 1999.

JOMINI, Regina Celia Mazoni. Uma educação para a solidariedade: contribuição ao estudo das concepções e realizações educacionais dos anarquistas na Republica Velha. Campinas, SP: Pontes, 1990.

LUIZZETTO, Flávio. Utopias anarquistas. São Paulo: Brasiliense, 1987.

MARTINS, José de Souza. O cativeiro de terra. 2. ed. São Paulo: LECH, 1981

MORIYÓN, F. G.. Educação libertária. Porto Alegre: Artes Médicas, 1989

PINHEIRO, Paulo Sérgio; HALL, Michael M. A classe operária no Brasil, 1989-1930. São Paulo: Alfa-Omega, 1979.

RAYNAUD, J. M..; AMBAUVES, G.. L'education Libertaire. Paris: Spartacus, 1978

RIBEIRO, Maria Rosa Alice. Condições de trabalho na indústria têxtil paulista (18701930). São Paulo: Hucitec, Ed. da UNICAMP, 1988.

RODRIGUES, Edgar. Os anarquistas trabalhadores italianos no Brasil. São Paulo: Global, 1984

Nacionalismo \& cultura social 1913-1922. Rio de Janeiro: Laemmert, 1972.

Trinta horas em Sorocaba. In: Biblioteca Sorocabana: história. Vol. 1. Sorocaba: Crearte, 2005, p. 49-53.

RODRIGUES, Leôncio Martins. Trabalhadores, sindicatos e industrialização. São Paulo: Brasiliense, 1974.

Revista HISTEDBR On-line, Campinas, n.33, p.109-121, mar.2009 - ISSN: 1676-2584 
SAES, Flávio Azevedo Marques. As ferrovias de São Paulo. São Paulo: HUCITE, Brasília: INL: 1981.

SILVA, Sergio. Expansão cafeeira e origens da indústria no Brasil. São Paulo: AlfaOmega, 1976.

TRAGTENBER, Maurício. O conhecimento expropriado e reapropriado pela classe operária Espanha 80. Educação e Sociedade, Campinas, vol. 7, p.53-62, Set. 1980.

TUDO sobre escola moderna. Disponível em <http://brasiliavirtual.info/tudosobre/escola-moderna/>. Acesso em 26.mai.2008.

Fontes primárias - Jornais e Revistas

A Cidade de Sorocaba $(1913,1915,1916)$

O Operário (1909-1913);

Diário de Sorocaba, (1880 - 1930);

O Ypanema (1872-1880)

Revista O fim do século, 1897

\footnotetext{
${ }^{1}$ Annuncios, Ypanema, Sorocaba, 10 out.1879; Annuncios, Diário de Sorocaba, Sorocaba, 11 maio 1883,9 out.1884, 12 dez.1884, 7 out.1886, 5 abr.1889.

${ }^{2}$ O jornal tinha como missão "defender a legião dos oprimidos que constitui o elemento primordial do progresso e conseqüentemente o da riqueza universal" (O Operário, 09/04/1911)

${ }^{3}$ Sobre a fábrica de tecidos Nossa Senhora da Ponte, a primeira do gênero em Sorocaba, não restavam dúvidas que por ser pioneira, havia sido dado "um passo gigantesco na senda do progresso da nossa terra" (O Operário, 19/02/1911).

4 No encaminhamento dessa proposta de educação libertária é notável as diferenças quantitativas e qualitativas no que se refere ao assunto. Isso ocorre, provavelmente, pelo encaminhamento das diferentes correntes representativas do movimento - mutualistas, coletivistas, comunistas. (Cf. TOMASI, 1973)

5"Vicente de Caria, italiano da Calábria (1873), veio para o Brasil em 1891, e não demorou em fixar residência em Sorocaba, numa colônia espanhola, em terras localizadas na encosta do Morro da Mariquinha. No ano de 1907, comprou uma chácara no bairro da Caputera e com sua família dedicou-se à plantação de cebolas: vivia um pouco do que produzia e um pouco do anarquismo. (...) Alguns anarquistas perseguidos de várias regiões do Brasil procuravam esconderijo na Chácara de Vicente de Caria. E uma vez ou outra, a polícia também dava batidas à procura de subversivos, obrigando Vicente a esconder companheiros de idéias, livros e jornais que recebia de São Paulo, do Rio de Janeiro, e até do exterior, no meio dos arbustos. (...)" (RODRIGUES, 2005, p. 49).

${ }^{6}$ Infelizmente, não foram encontradas outras informações sobre a escola da Chácara de Vicente de Caria e sobre a escola da Liga Operária de Sorocaba.
}

Artigo recebido em: 14/03/2009

Aprovado para publicação em: 15/05/2009

Revista HISTEDBR On-line, Campinas, n.33, p.109-121, mar.2009 - ISSN: 1676-2584 